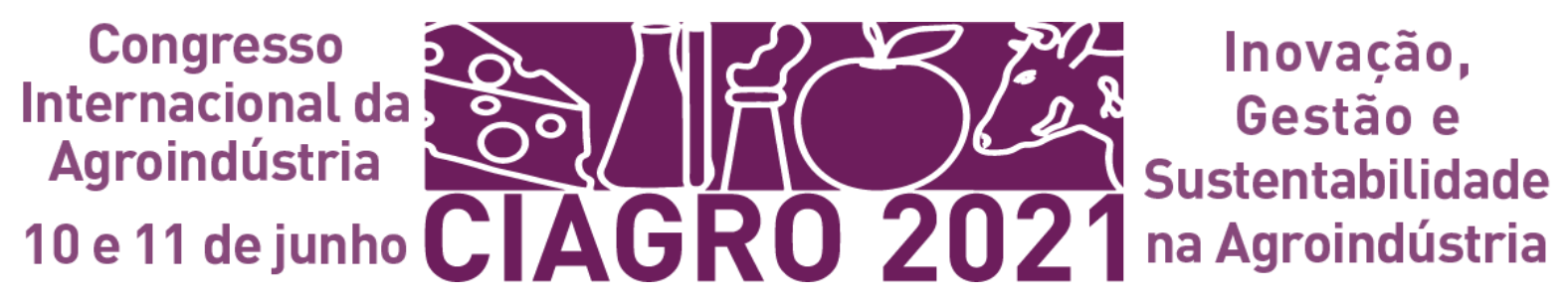

\title{
AVALIAÇÃO DA QUALIDADE MICROBIOLÓGICA DE QUEIJOS DE COALHO COMERCIALIZADOS EM LAVRAS-MG
}

\section{EVALUATION OF THE MICROBIOLOGICAL QUALITY OF COALHO CHEESES COMMERCIALIZED IN LAVRAS-MG}

Bruna Azevedo Balduinoㅜ; Anderson Henrique Venâncio²; Cássia Duarte Oliveira ${ }^{3}$; Roberta Hilsdorf Piccoli ${ }^{4}$

DOI: $\underline{\text { https://doi.org/10.31692/IICIAGRO.0259 }}$

\begin{abstract}
RESUMO
O queijo de coalho é um produto típico da região Nordeste do Brasil, que teve sua produção e consumo expandidos, consideravelmente, por todo o país. Devido ao seu alto teor nutritivo e características físicoquímicas favoráveis, ele se torna um meio ideal para o desenvolvimento de microrganismos patogênicos e deterioradores, o que pode causar alterações sensoriais, redução da vida útil e, até mesmo, riscos à saúde do consumidor. Desse modo, o trabalho teve como objetivo avaliar a qualidade microbiológica de três marcas de queijo de coalho (A, B, C) comercializadas na cidade de Lavras - MG. Para tanto, as amostras de queijo de coalho foram coletadas em um estabelecimento comercial, armazenadas em caixas isotérmicas com gelo e transportadas, imediatamente, ao Laboratório de Microbiologia de Alimentos, para a execução das análises microbiológicas. Os queijos foram avaliados quanto à quantificação de microrganismos aeróbios mesófilos, enterobactérias, Staphylococcus coagulase positiva e Escherichia coli, sendo todas as análises realizadas em triplicata com três repetições. Os resultados demonstraram que as três marcas estavam em condições higiênico-sanitárias satisfatórias e em conformidade com a legislação vigente com relação à presença de Staphylococcus coagulase positiva e Escherichia coli, já que não foi observada presença desses microrganismos nas amostras de queijos. No entanto, todas as amostras apresentaram contagens de enterobactérias e microrganismos aeróbios mesófilos, o que indica possíveis falhas de higiene durante as etapas de produção no laticínio. Portanto, é necessário utilizar uma matéria-prima de qualidade, realizar as boas práticas de fabricação e garantir uma higienização correta do ambiente de processamento, embalagens e utensílios, higiene pessoal dos colaboradores, armazenamento e comercialização adequados, de modo a garantir a qualidade do produto e a segurança dos consumidores.
\end{abstract}

Palavras-Chave: Controle microbiológico, Produtos lácteos, Queijos.

\begin{abstract}
Coalho cheese is a typical product from the Northeast region of Brazil, which had its production and consumption expanded considerably throughout the country. Due to its high nutritional content and favorable physicochemical characteristics, it becomes an ideal medium for the development of pathogenic and deteriorating microorganisms, which can cause sensory changes, reduced shelf life, and even risks to consumer health. Thus, the work aimed to evaluate the microbiological quality of three brands of Coalho cheese (A, B, C) marketed in the city of Lavras - MG. For this, the Coalho cheese samples were collected in a commercial establishment, stored in isothermal boxes with ice, and immediately transported to the Food Microbiology Laboratory to carry out microbiological analyses. Cheeses were evaluated to quantify aerobic mesophilic microorganisms, enterobacteria, positive

\footnotetext{
${ }^{1}$ Mestrado em Ciência dos Alimentos, Universidade Federal de Lavras, brunaazevedo.94@ hotmail.com

${ }^{2}$ Mestrado em Ciência dos Alimentos, Universidade Federal de Lavras, anderson123dfgh21@gmail.com

${ }^{3}$ Doutorado em Ciência dos Alimentos, Universidade Federal de Lavras, cassiaduartemg2@ @otmail.com

${ }^{4}$ Professora Titular, Universidade Federal de Lavras, rhpiccoli@ufla.br
} 
coagulase Staphylococcus, and Escherichia coli, with all analyses performed in triplicate with three replications. The results showed that the three brands were in satisfactory hygienic-sanitary conditions and following the current legislation, regarding the presence of positive coagulase Staphylococcus and Escherichia coli, since the presence of these microorganisms was not observed in the cheeses samples. However, all samples showed counts of enterobacterial and aerobic mesophilic microorganisms, which indicates possible hygiene failures during production stages in the dairy. Therefore, it is necessary to use a quality raw material, carry out good manufacturing practices and ensure correct hygiene of the processing environment, packaging and utensils, personal hygiene of employees, adequate storage and marketing, to guarantee product quality and consumer safety.

Keywords: Microbiological control, Dairy products, Cheeses.

\section{INTRODUÇÃO}

A produção de queijos é uma forma de conservação do leite, por meio de sua transformação em um produto mais estável, cujas características são mantidas (DIAS et al., 2016).

O queijo é um produto popular muito comum na alimentação da maioria da população. Por ser rico em nutrientes, torna-se um excelente meio para multiplicação de microrganismos, até mesmo os patogênicos. Desse modo, a contaminação microbiológica desses produtos é de extrema importância para a indústria, podendo causar um prejuízo econômico, e para a saúde pública, devido ao risco de ocasionar doenças de origem alimentar (LIMA; CARDOSO, 2019; OLIVEIRA et al., 2021; VILLAS BOAS et al., 2020; VISOTTO et al., 2011).

Dentre os diversos tipos de queijo, o queijo de coalho é um produto típico da região Nordeste do Brasil, muito popular e amplamente consumido pela população. Devido ao seu alto valor nutritivo e sabor agradável, sua produção e consumo se expandiram consideravelmente pelo país (BARROS et al., 2019; BEZERRA et al., 2017; MACHADO et al., 2021; SOUSA JÚNIOR et al., 2015).

Segundo o Regulamento Técnico de Identidade e Qualidade, presente na Instrução Normativa nº 30, do Ministério da Agricultura, Pecuária e Abastecimento (MAPA), o queijo de coalho é obtido pela coagulação do leite por meio de coalho ou outras enzimas coagulantes apropriadas, complementada, ou não, pela produção de bactérias lácteas selecionadas, e comercializado normalmente com até 10 dias de fabricação. É um queijo de média à alta umidade, de massa semicozida ou cozida e apresenta um teor de gordura nos sólidos totais, variável entre $35 \%$ e $60 \%$ (BRASIL, 2001).

Devido à sua composição, umidade e alto valor nutricional, esse queijo é um substrato ideal para o desenvolvimento de microrganismos. Desse modo, a utilização de matéria prima de má qualidade associada à falta de padronização do processo de produção, torna o produto mais susceptível à contaminação e uma possível fonte de toxinfecção alimentar. Essa 
contaminação por microrganismos patogênicos pode ser proveniente de manipuladores, do ambiente de produção ou do armazenamento do produto (BARROS et al., 2019; SOUSA JÚNIOR et al., 2015).

Dentre os microrganismos que se desenvolvem em queijos, destacam-se os coliformes totais e termotolerantes, bactérias aeróbias mesófilas, Staphylococcus coagulase positiva, Eschericha coli e bolores e leveduras. Uma vez presentes no alimento, eles são responsáveis por reduzir a qualidade do produto, além de serem um potencial risco à saúde do consumidor (SALVADOR et al., 2001).

Portanto, as condições higiênico-sanitárias durante a produção são essenciais para garantir um produto seguro aos consumidores, sendo necessário a realização de procedimentos como a pasteurização do leite cru e a aplicação das Boas Práticas de Fabricação (BPF), para evitar a contaminação por patógenos causadores de doenças transmitidas por alimentos (DTAs) (BASTOS; MARTINS; REGHIANTE, 2020; SILVA; BERTOLUCI; VIVAN, 2019).

Diante deste contexto, este trabalho teve como objetivo avaliar a qualidade microbiológica de três marcas de queijo de coalho comercializadas no município de LavrasMG.

\section{FUNDAMENTAÇÃO TEÓRICA}

O leite e os produtos lácteos vêm sendo utilizados pela humanidade há milhares de anos. Sua composição e propriedades específicas fazem com que eles sejam um meio ideal para o crescimento de diversos microrganismos (CANCINO-PADILLA et al., 2017).

A qualidade do leite depende dos seus parâmetros químicos e microbiológicos. Portanto, a compreensão de sua microbiota é importante para controlar as características qualitativas, sensoriais e de biossegurança dos produtos lácteos. Sendo que, alguns fatores como meio ambiente, processamento e armazenamento afetam a carga microbiana do leite e seus derivados, como os queijos (FUSCO et al., 2020; TILOCCA et al., 2020).

O queijo é um alimento nutritivo, suscetível à contaminação por microrganismos deterioradores e patogênicos, o que pode levar à alterações indesejáveis, redução da vida útil e transmissão de doenças alimentares, que podem causar riscos à saúde do consumidor (CHOI et al., 2016; RITOTA; MANZI, 2020).

O queijo de coalho também está associado a problemas de qualidade microbiológica. Principalmente, quando produzido de forma artesanal (DE FREITAS FILHO et al., 2020; MACHADO et al., 2021).

O consumo de queijos contaminados tem sido associado a casos e surtos de doenças de 
origem alimentar causadas por Listeria monocytogenes, Staphylococcus aureus, Escherichia coli, Salmonella entérica, entre outros (DE OLIVEIRA et al., 2017).

Alguns estudos realizados para avaliar a qualidade microbiológica de queijo de coalho, produzidos tanto de forma industrial, quanto artesanal, tem detectado a presença de Staphylococcus coagulase positiva, aeróbios mesófilos, E. coli, além de outros microrganismos, demonstrando que esses queijos nem sempre se encontram em conformidade com a legislação. Borges et al. (2003) avaliaram a qualidade higiênico-sanitária de 43 amostras de queijo de coalho produzidas em diferentes microrregiões do estado do Ceará e demostraram que todas as amostras apresentaram contagens de bolores e leveduras e de coliformes totais e termotolerantes, com confirmação de E. coli em 93,1\% das amostras. Também, verificaram a presença de Staphylococcus coagulase positiva em 93,1\% das amostras de Salmonella em $34,9 \%$ das amostras e Listeria sp. em 6,9\% das amostras de queijo.

Barbosa et al. (2011) avaliaram a qualidade microbiológica do queijo de coalho comercializado na feira livre do município de Solânea-PB e observaram alta contaminação por microrganismos aeróbios mesófilos, Staphylococcus aureus e coliformes totais e termotolerantes. O que indicou que os queijos não estavam em conformidade com a legislação vigente, sendo considerados impróprios para o consumo. Segundo os autores, a contaminação pode ter ocorrido por falhas de higiene durante as etapas de produção e comercialização do produto, ou devido ao uso de leite não pasteurizado.

Carvalho et al. (2019) analisaram amostras de queijo de coalho, não inspecionado, comercializados em estabelecimentos do município de Garanhuns-PE e verificaram a presença de coliformes totais e termotolerantes em 100\% das amostras; Salmonella spp. em 25\% das amostras e contagem de Staphylococcus coagulase positiva acima do permitido pela legislação, em $62,5 \%$ das amostras.

Entre as várias espécies de Staphylococcus, cinco (S. aureus, S. intermedius, S. delphini, S. schleleiferi subsp. Coagulans e S. hyicus) são capazes de produzir coagulase, uma enzima extracelular. Essas espécies são consideradas patógenos potencialmente sérios e, desse modo, a produção de coagulase é utilizada como uma indicação de patogenicidade entre as espécies de Staphylococcus. Sendo S. aureus, a espécie mais prevalente em surtos de intoxicação alimentar estafilocócica (DA SILVA et al., 2017; SILVA; GANDRA, 2004).

S. aureus é um patógeno de origem alimentar de grande importância em todo o mundo, por estar relacionado à frequentes contaminações de alimentos. Algumas de suas cepas são capazes de produzir enterotoxinas estafilocócicas, que, uma vez presentes nos alimentos, podem levar à intoxicação alimentar quando ingeridas. Leites e produtos lácteos são produtos que estão 
frequentemente relacionados à contaminação por esse patógeno (CRETENET; EVEN; LE LOIR, 2011).

Enterobactérias é o nome dado "vulgarmente" aos membros da família Enterobacteriaceae, a qual pertencem as bactérias Gram-negativas, em forma de bastonetes, anaeróbias facultativas, não formadoras de esporos e oxidase negativa. Essas bactérias podem estar presentes no solo, água, frutas, vegetais, plantas, carnes, ovos, grãos, insetos, animais e humanos. Algumas são patogênicas ao homem, sendo consideradas um problema de saúde pública em todo o mundo. Devido ao fato de serem sensíveis e facilmente inativadas por sanitizantes, são utilizadas como indicadores das condições de higiene dos processos de fabricação, pois se houver falhas no processo de sanitização, elas são capazes de colonizar vários setores das plantas de processamento (DA SILVA et al., 2017).

Pertencente à família Enterobacteriaceae, a Escherichia coli é uma bactéria comumente presente na microflora do trato intestinal de humanos e animais de sangue quente, que possibilita a contaminação dos alimentos por falhas higiênico-sanitárias durante o processamento. Algumas de suas cepas podem causar doenças intestinais e extra intestinais, devido a seus fatores de virulência, que afetam diversos processos celulares. Os surtos de $E$. coli tem sido associados à ingestão de alimentos contaminados como carnes, maionese, cidra de maçã, vegetais e produtos lácteos (BHUNIA, 2008; KAPER; NATARO; MOBLEY, 2004; KASNOWSKI et al., 2007; ROSA; BARROS; SANTOS, 2016).

Os microrganismos aeróbios mesófilos podem ser utilizados para avaliar a qualidade do produto, já que suas altas contagens podem indicar uma sanitização ineficiente, falhas durante o processamento, utilização de matéria-prima de má qualidade e informações sobre a vida útil do produto. Eles não podem ser considerados um indicador de segurança, já que sua presença não está diretamente relacionada à presença de patógenos ou toxinas (DA SILVA et al., 2017).

Alguns estudos têm demonstrado a presença desses microrganismos em queijos. Silva e Ferreira (2021) investigaram a qualidade microbiológica de queijos Minas frescal, produzidos de forma industrial e artesanal comercializados na cidade de Uberlândia, e perceberam que todas as amostras de produção artesanal apresentaram uma alta população de mesófilos, encontrando-se em condições higiênico-sanitárias insatisfatórias. Melo et al. (2013) avaliaram a qualidade microbiológica de queijo de coalho fabricado e comercializado na Região Norte do estado do Ceará. Para tanto, as amostras foram coletadas em três pontos comerciais e, após as análises microbiológicas, observaram que as contagens de bactérias mesófilas variaram nos três pontos de coleta de $3,7 \times 10^{3}$ a $1,3 \times 10^{5} \mathrm{UFC} / \mathrm{g}$, estando estes microrganismos presentes em todas as amostras, o que indicou más condições de higiene durante a fabricação, manuseio ou 
comercialização.

Várias são as fontes de contaminação do produto pelos microrganismos citados e demais microrganismos patogênicos, que são responsáveis por causar toxinfecções alimentares. Essa contaminação pode ocorrer devido à utilização de matéria-prima contaminada, práticas inadequadas de manipulação, condições higiênicas precárias do ambiente de produção, equipamentos e estrutura operacional deficientes, falta de higiene dos manipuladores e condições inadequadas de armazenamento e comercialização (FERREIRA, 2006; GARCIA et al., 2017).

Portanto, é necessário ter um controle de todos os processos dentro da cadeia produtiva do queijo, partindo desde o momento da ordenha, para garantir que não haja falhas de higiene e evitar qualquer forma de contaminação por microrganismos. Além de realizar as boas práticas de fabricação e capacitação dos manipuladores, de modo a reduzir os riscos de contaminação e garantir um alimento seguro aos consumidores.

\section{METODOLOGIA}

\section{Local de condução do experimento}

As análises microbiológicas foram realizadas no laboratório de Microbiologia de Alimentos, no Departamento de Ciência dos Alimentos (DCA), da Universidade Federal de Lavras (UFLA), Lavras-MG, Brasil.

\section{Coleta, manutenção e preparo das amostras}

Amostras de três marcas, identificadas como A, B e C, de queijo de coalho sob registro do Serviço de Inspeção Federal (SIF), provenientes de laticínios de Minas Gerais, foram coletadas em um supermercado na cidade de Lavras-MG. As amostras foram acondicionadas em caixas isotérmicas com gelo $\left(4^{\circ} \mathrm{C}\right)$ e transportadas, imediatamente, para o Laboratório de Microbiologia de Alimentos do DCA/UFLA para posterior realização das análises microbiológicas. Todos os queijos encontravam-se dentro do prazo de validade.

Inicialmente, foi realizada uma higienização da bancada, embalagm dos queijos e demais utensílios com álcool $70 \%(\mathrm{~m} / \mathrm{v})$. Com auxílio de uma tesoura previamente esterilizada, as embalegens dos queijos foram abertas para retirada, de forma asséptica, de unidades analíticas de $25 \mathrm{~g}$ de cada amosta, que foram transferidas para um saco plástico estéril, contendo $225 \mathrm{~mL}$ de Caldo Citrato de Sódio 2\%. As amostras foram homegeneizadas em homogeneizador tipo Stomacher (Seward Stomacher 400 Lab) a 490 golpes/min, durante 5 
minutos, para obtenção da diluição inicial $\left(10^{-1}\right)$. Posteriormente, realizou-se diluições seriadas a partir da transferência de uma alíquota de $1 \mathrm{~mL}$ da amostra diluída (diluição $10^{-1}$ ) para um tubo contendo $9 \mathrm{~mL}$ de água peptonada $0,1 \%(\mathrm{~m} / \mathrm{v})$ e assim, sucessivamente, até atingir a diluição $10^{-4}$.

Foram realizadas análises para identificação de Staphylococcus coagulase positiva, contagem total de enterobactérias, contagem de Escherichia coli e contagem padrão de microrganismos mesófilos aeróbios, conforme à metodologia proposta por Da Silva et al. (2017). Todas as análises foram realizadas com três repetições, em triplicata. Para tanto, foram avaliadas uma amostra de cada marca de queijo de coalho, sendo a triplicata realizada a partir de uma mesma amostra de queijo. Após o plaqueamento das amostras em triplicata (três placas de Petri para cada diluição) e incubação das placas, foram selecionadas para contagem as placas que obtiveram entre 25 e 250 colônias e os resultados foram expressos, pela média aritmética dos valores encontrados para cada microrganismo avaliado, em unidades formadoras de colônia por grama de amostra (UFC/g).

\section{Contagem total de enterobactérias}

A quantificação de enterobactérias foi feita pelo método de contagem padrão em placas, utilizando-se o Ágar Vermelho Violeta Bile Glicose (VRBG). Desse modo, realizou-se a técnica de plaqueamento em profundidade, na qual alíquotas de $1 \mathrm{~mL}$ de cada diluição foram transferidas para placas de Petri estéreis, com subsequente adição do meio VRBG, previamente fundido e resfriado, seguida de homogeneização das placas e, após completa solidificação do meio, adição de uma sobrecamada. As placas foram invertidas e incubadas a $35^{\circ} \mathrm{C} / 24 \mathrm{~h}$. Após esse período, realizou-se a contagem de colônias típicas, sendo o resultado expresso em unidades formadoras de colônia por grama de amostra (UFC/g).

\section{Contagem de Staphylococcus coagulase positiva}

Foram selecionadas três diluições adequadas e inoculados alíquotas de $0,1 \mathrm{~mL}$ de cada diluição em placas de Petri estéreis, contendo o meio Ágar Vogel-Johnson, suplementado com solução de telurito de potássio $1 \%$, para realização do plaqueamento em superfície. As placas foram incubadas invertidas a $37^{\circ} \mathrm{C} / 48 \mathrm{~h}$ e, após esse período, as amostras que aprsentaram colônias típicas foram submetidas ao teste de coagulase. Para tanto, 5 colônias típicas de cada placa foram transferidas para tubos contendo caldo BHI e estes foram incubados a $37^{\circ} \mathrm{C} / 24 \mathrm{~h}$. Posteriormente, foi adicionado $0,3 \mathrm{~mL}$ da cultura em tubos estéreis com 0,3 $\mathrm{mL}$ de plasma de coelho, seguido de incubação a $37{ }^{\circ} \mathrm{C} / 6 \mathrm{~h}$ para verificar a produção de coagulase. Em caso 
A

AVALIAÇÃO DA QUALIDADE MICROBIOLÓGICA DE QUEIJOS DE COALHO

negativo, os tubos foram incubados por $24 \mathrm{~h}$. Tmbém foram realizados os testes bioquímicos de catalase, DNASE e capacidade de reduzir o manitol.

\section{Contagem de Escherichia coli}

Alíquotas de $0,1 \mathrm{~mL}$ das diluições foram transferidas para placas de Petri estéreis, contendo o meio de cultura Hektoen Enteric Agar, para realização do plaqueamento em superfície. Posteriormente, as placas foram incubadas invertidas a $37^{\circ} \mathrm{C} / 24 \mathrm{~h}$ e, após incubação, foram selecionadas 3 colônias características de E. coli, de cada placa, e essas foram submetidas às provas bioquímicas de Indol, Vermelho de Metila, teste de Voges-Proskauer e Citrato de Simmons para confirmação.

\section{Contagem padrão de aeróbios mesófilos}

A contagem total de aeróbios mesófilos foi realizada pela técnica de plaqueamento em profundidade. Desse modo, foram selecionadas três diluições adequadas e alíquotas de $1 \mathrm{~mL}$ de cada diluição foram transferidas para placas de Petri estéreis, com subsequente adição do meio de cultura Plate Count Agar (PCA), previamente fundido e resfriado. As placas foram homogeneizadas e, após solidificação do meio, foram invertidas e incubadas a $35^{\circ} \mathrm{C} / 48 \mathrm{~h}$. Após incubação, foram selecionadas para contagem, placas contendo de 25 a 250 colônias e o resultado foi expresso em UFC/g de amostra.

\section{RESULTADOS E DISCUSSÃO}

A contagem dos microrganismos avaliados em diferentes marcas de queijo coalho (A, B e C) pode ser observada na Tabela 1 , na qual os resultados foram expressos pela média da contagem de 3 placas.

Tabela 1. Contagem de Staphylococcus coagulase positiva, Aeróbios Mesófilos, Enterobactérias e Escherichia coli em queijos de coalho.

\begin{tabular}{ccccc}
\multicolumn{2}{c}{ coli em queijos de coalho. } & & & \\
\hline Marcas & $S$. coagulase positiva & Aeróbios mesófilos & Enterobactérias & coli \\
\hline A & $<1,0 \times 10^{1}$ & $3,3 \times 10^{5}$ & $3,8 \times 10^{5}$ & $<1,0 \times 10^{1}$ \\
B & $<1,0 \times 10^{1}$ & $2,3 \times 10^{5}$ & $1,53 \times 10^{3}$ & $<1,0 \times 10^{1}$ \\
C & $<1,0 \times 10^{1}$ & $7,8 \times 10^{5}$ & $2,03 \times 10^{3}$ & $<1,0 \times 10^{1}$ \\
\hline
\end{tabular}

Fonte: Própria (2021)

De acordo com a Tabela 1, as três marcas analisadas estavam em condições higiênicosanitárias satisfatórias e em conformidade com a legislação (BRASIL, 2019), com relação à presença de Staphylococcus coagulase positiva e Escherichia coli. Já que, a Instrução 
Normativa $n^{\circ}$ 60, de 23 de dezembro de 2019, da Agência Nacional de Vigilância Sanitária (ANVISA), estabelece um limite de $10^{3} \mathrm{UFC/g}$ para $S$. coagulase positiva e E. Coli em queijos e a presença desses microrganismos não foi observada em nenhuma amostra de queijo coalho analisada.

No entanto, todas as amostras apresentaram contagens de enterobactérias e microrganismos aeróbios mesófilos, que embora não possuam um valor limite preconizado pela legislação, indicam possíveis falhas de higiene durante a produção.

Na literatura, é possível encontrar outros estudos que, também, avaliaram a qualidade microbiológica de queijo de coalho. Sousa et al. (2014) avaliaram os padrões microbiológicos de queijos de coalho com e sem inspeção, comercializados em diferentes estados do Nordeste do Brasil. Eles verificaram que, das 104 amostras analisadas, 100 não estavam em conformidade com a legislação para Staphylococcus coagulase positiva, 32 amostras não seguiam a padronização para coliformes termotolerantes e em apenas uma amostra foi detectada a presença de Salmonella spp. Sendo que, tanto as amostras de queijo coalho artesanal, quanto as industrializadas com inspeção encontravam-se, em sua maioria, fora do padrão exigido pela legislação.

Pimentel (2019) avaliou a qualidade microbiológica de 40 amostras de queijo coalho comercializados na cidade de Manaus-AM, sendo 20 amostras não fiscalizadas, comercializadas em feiras, e 20 amostras fiscalizadas, comercializadas em supermercados. Foram encontrados valores de coliformes termotolerantes acima do limite permitido pela legislação, enquanto $20 \%$ das amostras de supermercados e $60 \%$ das amostras de feiras apresentaram contagens de Staphylococcus coagulase positiva acima do permitido pela legislação. Com relação aos microrganismos mesófilos, foi encontrado um valor esperado, embora os queijos provenientes de feiras tenham apresentado maiores contagens.

Oliveira et al. (2010) analisaram a qualidade microbiológica do queijo de coalho comercializado no município do Cabo de Santo Agostinho, em Pernambuco. Das 42 amostras analisadas, 40 estavam fora dos padrões microbiológicos estabelecidos pela legislação, sendo que $80,95 \%$ das amostras apresentaram valores acima do permitido para coliformes termotolerantes; 76,19\% apresentaram contagens de Staphylococcus coagulase positiva acima da legislação e em 64,29\%, foi detectada a presença de E. coli.

Por meio desses estudos é possível perceber que, embora o queijo de coalho tenha uma certa relevância cultural e socioeconômica, ele também está vinculado a uma reputação negativa, devido a problemas relacionados aos padrões de qualidade microbiológica. Principalmente, quando é produzido de forma artesanal (MACHADO et al., 2021). 
A contaminação por microrganismos patogênicos e deterioradores pode ocorrer em diversas etapas de toda a cadeia produtiva do queijo. A presença de patógenos no leite cru pode ser proveniente do ambiente da fazenda, excreções do úbere de animais infectados ou de falhas de higiene durante o processo de ordenha (KOUSTA et al., 2010). Algumas práticas como a higienização dos tetos da vaca, higienização vigorosa dos baldes, latas; e dos demais equipamentos como os utensílios utilizados durante a ordenha e o controle da temperatura do tanque de expansão contribuem para a redução da carga microbiana e melhora da qualidade microbiológica do leite cru (ALVES; DA SILVA; IGARASI, 2013; MATSUBARA et al., 2011).

No entanto, ainda é necessário que este leite passe por um processamento térmico, como a pasteurização, para eliminar os patógenos e garantir que eles não passem para a planta de processamento. Sendo que, este procedimento também deve ser monitorado para que não ocorra falhas no pasteurizador que resultem em uma pasteurização ineficiente, que não seja capaz de eliminar todos os microrganismos presentes. Além disso, é necessário realizar a higienização correta do pasteurizador e das tubulações para que não ocorra formação de biofilmes, que se tornam uma fonte de contaminação para o leite pasteurizado.

Falhas higiênico-sanitárias durante o processamento também podem levar a contaminação dos queijos. Os manipuladores, matéria-prima, ambiente de processamento e embalagens podem ser causas de contaminação. Portanto, é necessário seguir as boas práticas de fabricação e garantir uma correta higienização do ambiente de produção, realizando-se sempre a pulverização do ar e limpeza do chão da fábrica, higienização das mãos dos colaboradores, dos equipamentos e utensílios, como os tanques, mesas, formas, lira utilizados na fabricação do queijo de coalho e das embalagens. Além, de garantir a qualidade da matériaprima utilizada e um armazenamento adequado dos queijos, para evitar o desenvolvimento de possíveis patógenos alimentares.

\section{CONCLUSÕES}

As análises microbiológicas demonstraram que as três marcas de queijo de coalho analisadas estavam em conformidade com a legislação vigente, com relação a contagem de Staphylococcus coagulase positiva e Escherichia coli, já que não foi observada presença desses microrganismos nas amostras. No entanto, para considerar os queijos aptos ou não ao consumo, segundo a legislação, também é necessário avaliar a presença de Salmonella e enterotoxinas estafilocócicas. Além disso, foram observadas altas contagens de enterobactérias e aeróbios mesófilos nos queijos, indicando possíveis falhas higiênico-sanitárias que podem ter ocorrido 
durante o processo de produção, armazenamento, transporte e comercialização. Portanto, é necessário realizar melhorias no processo de produção, além de ter uma maior fiscalização, com o intuito de orientar e conscientizar os produtores e manipuladores de queijos quanto à utilização adequada das boas práticas de fabricação, de modo a melhorar a qualidade do produto e não oferecer riscos à saúde do consumidor.

\section{REFERÊNCIAS}

ALVES, B. G.; DA SILVA, T. H.; IGARASI, M. S. Manejo de ordenha. PUBVET, v. 7, n. 6, p. 420-548, 2013.

BARBOSA, F. R. et al. Avaliação microbiológica do queijo coalho comercializada na feira livre do município de Solânea-PB. Caderno Verde de Agroecologia e Desenvolvimento Sustentável, v. 1, n. 1, p. 1, 2011.

BARROS, D. D. et al. Coalho cheese with incorporated chitosan and as a coating: effect on the viability of Staphylococcus aureus and sensory acceptance. Semina-Ciencias Agrarias, v. 40, n. 6, p. 3477-3491, 2019.

BASTOS, R. B.; MARTINS, O. A.; RAGHIANTE, F. Hygienic-sanitary quality of fresh Minas cheese: a review. Revista Brasileira de Higiene e Sanidade Animal, v. 14, n. 3, p. 1-12, 2020.

BEZERRA, D. E. L. et al. Avaliação microbiológica de queijo de coalho comercializado na feira livre de Sousa-Paraíba. Divulgação Científica e Tecnológica do IFPB, v. 37, p. 85-91, 2017.

BHUNIA, A. K. Foodborne microbial pathogens: mechanisms and pathogenesis. New York: Spring Science Business, 2008.

BORGES, M. de F. et al. Microrganismos patogênicos e indicadores em queijo de coalho produzido no Estado do Ceará, Brasil. Boletim do Centro de Pesquisa de Processamento de Alimentos, v. 21, n. 1, p. 31-40, 2003.

BRASIL. Ministério da Agricultura Pecuária e Abastecimento. Instrução normativa $\mathrm{n}^{\circ}$ 30, de 26 de Junho de 2001. Aprova o Regulamento Técnico de Identidade e Qualidade de Manteiga da Terra ou Manteiga de Garrafa; Queijo de Coalho e Queijo de Manteiga. Diário Oficial da União, p. 13, Brasília, 2001.

BRASIL. Ministério da Saúde. Agência Nacional de Vigilância Sanitária. Instrução Normativa - IN n ${ }^{\circ}$ 60, de 23 de dezembro de 2019. Estabelece as listas de padrões microbiológicos para alimentos. Diário Oficial da União, p. 133, Brasília, 2019.

CANCINO-PADILLA, N. et al. Foodborne bacteria in dairy products: Detection by molecular techniques. International Journal of Agriculture and Natural Resources, v. 44, n. 3, p. 215$229,2017$.

CARVALHO, M. G. J. D. et al. Qualidade microbiológica do queijo de coalho não inspecionado adquiridos em estabelecimentos comerciais de Garanhuns-PE. Higiene 
Alimentar, v. 33, n. 288/289, p. 2065-2070, 2019.

CHOI, K. H. et al. Cheese microbial risk assessments-a review. Asian-Australasian Journal of Animal Sciences, v. 29, n. 3, p. 307, 2016.

CRETENET, M.; EVEN, S.; LE LOIR, Y. Uneveiling Staphylococcus aureus enterotoxin production in dairy products: a review of recente advances to face new challenges. Dairy Science \& Technology, v. 91, n. 2, p. 127-150, 2011.

DA SILVA, N. et al. Manual de métodos de análise microbiológica de alimentos e água. São Paulo: Editora Blucher, 2017.

DE FREITAS FILHO, J. R. et al. Avaliação dos parâmetros físico-químicos e microbiológicos de queijo coalho comercializado em feiras livres. Almanaque Multidisciplinar de Pesquisa, v. 7, n. 2, p. 166-181, 2020.

DE OLIVEIRA, C. A. F. et al. Pathogenic bacteria in cheese, their implications for human health and prevention strategies. In: Nutrients in Dairy and their Implications on Health and Disease. United States: Academic Press, 2017.

DIAS, B. F. et al. Qualidade microbiológica e físico-química de queijo minas frescal artesanal e industrial. Revista de Agricultura Neotropical, v. 3, n. 3, p. 57-64, 2016.

FERREIRA, S. M. D. S. Contaminação de alimentos ocasionada por manipuladores. Brasília, 2006. 48 p. Monografia (Especialização em Qualidade em Alimentos). Universidade de Brasília-Centro de Excelência em Turismo, CET, 2006.

FUSCO, V. et al. Microbial quality and safety of milk and milk products in the $21 \mathrm{st}$ century. Comprehensive Reviews in Food Science and Food Safety, v. 19, n. 4, p. 20132049, 2020.

GARCIA, E. P. et al. Qualidade microbiológica de queijos minas frescal e ricota comercializados na Região Metropolitana de Campinas-SP. Higiene Alimentar, v. 31, n. 264/265, p. 132-137, 2017.

KAPER, J. B.; NATARO, J. P.; MOBLEY, H. L. T. Pathogenic escherichia coli. Nature Reviews Microbiology, v. 2, n. 2, p. 123-140, 2004.

KASNOWSKI, M. C. et al. Escherichia coli: uma revisão bibliográfica. Higiene Alimentar, v. 21, n. 154, p. 44-48, 2007.

KOUSTA, M. et al. Prevalence and sources of cheese contamination with pathogens at farm and processing levels. Food Control, v. 21, n. 6, p. 805-815, 2010.

LIMA, A. A.; CARDOSO, A. J. V. S. Qualidade microbiológica de queijo Minas frescal, artesanal, comercializados em feiras livres do Distrito Federal. Brazilian Journal of Development, v. 5, n. 9, p. 13673-13688, 2019.

MACHADO, T. D. X. et al. Effect of the application of probiotic strains of Enterococcus faecium on the physicochemical and sensory characteristics of coalho cheese. Semina-Ciencias 
Agrarias, v. 42, n. 1, p. 167-177, 2021.

MATSUBARA, M. T. et al. Boas práticas de ordenha para redução da contaminação microbiológica do leite no agreste Pernambucano. Semina: Ciências Agrárias, v. 32, n. 1, p. 277-285, 2011.

MELO, M. B. et al. Avaliação microbiológica do queijo do tipo coalho comercializado na cidade de Sobral, CE. Higiene Alimentar, v. 27, n. 222/223, p. 92-96, 2013.

OLIVEIRA, K. A. et al. Qualidade microbiológica do queijo de coalho comercializado no Município do Cabo de Santo Agostinho, Pernambuco, Brasil. Arquivos do Instituto Biológico, v. 77, n. 3, p. 435-440, 2010.

OLIVEIRA, M. D. et al. Hygienic-health quality and microbiological hazard of clandestine Minas Frescal cheese commercialized in north Tocantins, Brazil. Semina-Ciencias Agrarias, v. 42, n. 2, p. 679-694, 2021.

PIMENTEL, E. T. Qualidade de queijo coalho comercializado em Manaus, AM. Manaus, 2019. 51 p. Dissertação (Mestrado em Ciência Animal). Faculdade de Ciências Agrárias, UFAM, 2019.

RITOTA, M.; MANZI, P. Natural preservatives from plant in cheese making. Animals, v. 10, n. 4, p. 749, 2020.

ROSA, J. L.; BARROS, R. F.; SANTOS, M. O. Características da Escherichia coli enterohemorrágica (EHEC). Saúde \& Ciência em Ação, v. 2, n. 1, p. 66-78, 2016.

SILVA, H. de A.; FERREIRA, A. C. M. Indicadores higiênicos sanitários em queijos do tipo minas frescal na cidade de Uberlândia-MG. Revista Brasileira Multidisciplinar, v. 24, n. 1, 2021.

SILVA, L. F. B.; BORTOLUCI, F.; VIVAN, A. C. P. Análise microbiológica de queijos tipo minas frescal oriundos de diferentes formas de produção. SALUSVITA, v. 38, n. 2, p. 329343, 2019.

SILVA, W. P.; GANDRA, E. A. Estafilococcus coagulase positiva: patógenos de importância em alimentos. Higiene Alimentar, v. 18, n. 122, p. 32-40, 2004.

SALVADOR, M. et al. Avaliação da qualidade microbiológica do queijo de prato e parmesão ralado. Boletim do Centro de Pesquisa e Processamento de Alimentos, v. 19, n. 1, p. 65-74, 2001.

SOUSA JÚNIOR, D. L. de et al. Análise bacteriológica de queijos tipo coalho comercializados no município de Crato, Ceará. Revista Interfaces: Saúde, Humanas e Tecnologia, v. 3, n. 8, 2015.

SOUSA, A. Z. B. et al. Aspectos físico-químicos e microbiológicos do queijo tipo coalho comercializado em estados do nordeste do Brasil. Arquivos do Instituto Biológico, v. 81, n. 1, p. 30-35, 2014. 
TILOCCA, B. et al. Milk microbiota: Characterization methods and role in cheese production. Journal of proteomics, v. 210, p. 103534, 2020.

VILLAS BOAS, A. F. et al. Qualidade microbiológica de queijos Minas Frescal artesanais e industrializados. Brazilian Journal of Development, v. 6, n. 10, p. 83536-83552, 2020.

VISOTTO, R. G. et al. Queijo Minas Frescal: perfil higiênico-sanitário e avaliação da rotulagem. Revista do Instituto Adolfo Lutz, v. 70, n. 1, p. 8-15, 2011. 